units will have nursing officers, some will have senior nursing officers. The units will run on nurse patient ratios ranging from 1.5:1 to 2.8:1 with a mean of around 2:1. Part of this variation is a reflection of the different shift systems. Most RSUs will appoint principal psychologists to head the establishment, but staffing plans vary from a single psychologist post to complements as large as six. Occupations have been approached in various ways from the occupational therapy model to rehabilitation managers, technical instructors, gymnasts and even physiotherapists.

\section{Research}

Part of the remit for RSUs, according to Butler, was as a centre for research. Buildings such as the Bethlem RSU and Trent RSU are well endowed for such a function. It is important that each Region pursues this course in order to make firmer the academic base of forensic psychiatry. There is an RSU research unit based in Birmingham and they are about to commence a detailed comparative clinical research study on seven regional secure units.

Conclusions

The rate of progress around the country and the models chosen are various. Those Regions with little forensic psychiatry involvement in planning have run into problems with the structure, site of unit, and its function as a base for a forensic service. Other Regions have been led by the forensic psychiatrist into adopting differing RSU and service models. Over the next two years there will be dramatic changes. Of the 717 planned permanent places (excluding mental impairment and adolescent units), 120 were completed by March 1983, although only 20 beds were open. By March 1984 around 344 beds will be completed with between 80 to 110 functioning beds, and by late 1984, with further RSUs opening, we may have well over 200 staffed RSU beds. We are now reaching the situation whereby the limiting factor is not the building of RSUs, but the staff (especially nursing) to run them. The problem is not only in recruitment. Recently a number of Regions have attempted to cut back their share of the revenue allocation, putting not only the security of these units at risk but their whole philosophy. It will be interesting to see how the picture develops.

The views, ideas and proposals expressed in this paper are not necessarily those of the DHSS.

\title{
What Do Psychiatrists Understand by Formulation?
}

\author{
A Survey of Clinicians in a Group of Hospitals in London \\ Julie A. Hollyman, Clinical Research and Honorary Senior Registrar and Loic Hemsi, Consultant Psychiatrist, St
} George's Hospital Medical School, London SW17

Following the taking of a psychiatric history and the examination of the mental state, it is standard practice to prepare a formulation (Institute of Psychiatry, 1973; Slater and Roth, 1977; Royal College of Psychiatrists, 1979; Garrick and Stotland, 1982). Indeed, the concept of formulation is central to the psychiatrist's approach.

The authors' renewed interest in the formulation arose from a discussion of the experience of one of them during the clinical examination for the MRCPsych in 1981. She was disconcerted to find that she and the examiner differed substantially as to the meaning of the term and what was to be included in the formulation. This was thought not to be unique, and it seemed probable that the term was being given different interpretations. An examination of the literature extant in the autumn of 1981 confirmed that view.

In April 1979, the Association of Psychiatrists in Training (APIT), in an open letter to the Bulletin criticizing the MRCPsych examination, questioned whether examiners agree among themselves about the notion of formulation. That letter provoked some correspondence, but the College did not itself make a response.
In June 1979, the 'Scribe's Column' in the Bulletin outlined four views on formulation (including APIT's own) and concluded that a diagnostic formulation is a 'summary of the relevant genetic, constitutional and personality factors and their interaction with aetiological factors, taking into account the patient's life situation, together with a provisional diagnosis and plan of treatment.' This paper was reprinted in Handbook for Inceptors and Trainees in Psychiatry, alongside another article entitled 'The MRCPsych Examination' where the formulation was described as 'a summary of the essential features of the history, mental state and physical examination.'

One might reasonably expect to find more guidance in standard textbooks. In fact, if there is reference at all to formulation, it is cursory and opinion is not uniform. Some authors (Myre Sim, 1974; Anderson and Trethowan, 1973; Hill et al, 1979) do not consider the question at all. Amongst authors who do consider formulation, two main schools of thought appear. On one side are those (Institute of Psychiatry, 1973; Priest and Steinert, 1977; Slater and Roth, 1977; Curran et al, 1980) who tend to the view that the 
formulation is a discussion of the diagnosis in terms of the patient's previous experience and aetiological factors, and that it should contain a proposal as to management and probably an estimate of prognosis. In contrast, Kendell (1975) and Tredgold and Wolf (1970) hold that formulation and diagnosis are mutually exclusive, the former being a description of the patient in terms of personality, relationships, past stresses and the development of symptoms.

These differences and uncertainties led the authors to undertake a survey in October 1981 in order to test the hypothesis that there are different notions as to what a formulation is and what it should include. While the present paper was being prepared, interest in the subject was highlighted by a letter to the Bulletin in September 1982 by Drs Greenberg, Szmukler and Tantam which reported similar doubts and which suggested guidelines on formulating a case for the MRCPsych examination.

\section{Method}

Psychiatrists of all grades of seniority practising in the St George's group of hospitals were asked in a letter to submit a statement 'embodying your view of what a formulation should contain.' It was suggested that replies could be anonymous, if this was desired, but that NHS grade should be recorded.

The use of a questionnaire was considered but rejected, as it was felt that it would leave the replies open to bias or to suggestion from its wording.

Not unexpectedly, the method chosen gave rise to problems in the analysis of the replies, but a method for examination of the content was devised. Eleven individual items were identified in the statements: history, mental state, physical examination, investigations, differential diagnosis, single diagnosis, psychodynamics, aetiology, management, prognosis and length.

The answers to the circular letter were then scored as including an item if reference to it was made, explicitly or implicitly. The two authors performed the analysis separately. In most cases where agreement between them was not complete, the disagreement related to one item only and it was dispelled by discussion or, where doubt remained, it was resolved by asking the respondents to provide explanations for the contentious terms. (Ultimately, one reply was omitted from the analysis as it was so worded as to make the application of the method of content analysis impossible.)

\section{Results}

Response

Of 28 consultants circulated, 22 replied ( 79 per cent); of 15 senior registrars circulated, 11 replied (73 per cent); and of 23 registrars/senior house officers circulated, 16 replied (70 per cent). Thus, of a total of 66 circulated, 49 replied-a response rate of 74 per cent, high at all grades of seniority.
Items

The table shows for each item the number of doctors (expressed as a percentage) at each level of seniority who included that item in their formulation.

TABLE

Inclusion of items in formulation, by seniority

\begin{tabular}{lcccc}
\hline Item & $\begin{array}{c}\text { Consultants } \\
(\%)\end{array}$ & $\begin{array}{c}\text { SRs } \\
(\%)\end{array}$ & $\begin{array}{c}\text { SHO/Reg. } \\
(\%)\end{array}$ & $\begin{array}{c}\text { Total } \\
\text { sample } \\
(\%)\end{array}$ \\
\hline History & 81 & 82 & 81 & 81 \\
Mental state & 57 & 64 & 38 & 52 \\
Physical examination & 10 & 18 & 13 & 13 \\
Differential diagnosis & 76 & 64 & 50 & 65 \\
Single diagnosis & 24 & 36 & 37 & 31 \\
Psychodynamics & 33 & 45 & 19 & 31 \\
Aetiology & 43 & 45 & 56 & 48 \\
Management & 81 & 64 & 81 & 77 \\
Prognosis & 67 & 55 & 69 & 65 \\
Length & 29 & 0 & 44 & 27 \\
\hline
\end{tabular}

The overwhelming majority of respondents in all grades referred to history in their formulation. Inclusion of the mental state examination was less certain, averaging 50 per cent in the sample. Physical examination and investigations were mentioned infrequently.

If differential diagnosis and single diagnosis are considered together, then virtually all replies included reference to the diagnosis. There is a slight trend for increasing seniority to lead to a preference for the differential diagnosis rather than for a single diagnosis. Psychodynamics was included by only one-third of the subjects, and by comparatively fewer of the most junior doctors. Aetiology was another doubtful inclusion, appearing in 50 per cent of the statements only.

Management plans were regarded by all doctors to be as important as the history, but for prognosis there were differences of opinion. Length was an interesting category: it seemed largely to be a preoccupation of the registrar and senior house officer grades (44 per cent), which was lost on promotion to the grade of senior registrar ( 0 per cent)!

The majority view of the formulation thus seemed to be that it should contain details of history, diagnosis and management, but that it should not include physical examination, investigation or psychodynamics. There was no consensus as to whether mental state, aetiology and prognosis should be incorporated. There was doubt also about whether length was an item worthy of consideration and much diversity about how long a formulation should be: comments ranged from 'one and a half sides of A4 paper' to 'not more than three sentences'.

\section{Discussion}

This survey lends support to the hypothesis that there are 
different opinions about the formulation on the part of psychiatrists. On studying the exact wording of the replies, it is also clear that to a certain extent the content of the formulation is influenced by the author's perception of its function.

The booklet produced by the Institute of Psychiatry, Notes on Eliciting and Recording Clinical Information, differentiates clearly between 'summary' and 'formulation'. The former is regarded as a 'concise description of all the important aspects of the case', whereas the latter is an 'assessment of the case rather than a restatement of the facts'. This distinction was drawn by some of the respondents, but not by all. Phrases such as 'a summing-up' and 'a summary of the case' were used to describe the notion that a formulation should be the repetition of the important facts of the history, the description of the mental state and a diagnosis.

The direction in which it was thought that the argument should progress was also variable. Some authors preferred to argue from the starting point of the differential diagnosis and then bring in the relevant facts, whereas others preferred to relate the facts and from there arrive at a diagnosis.

In general, psychiatric colleagues were in favour of including management in the formulation, but some specifically excluded that item (the only one positively identified for exclusion in this way).

The authors were surprised that so few respondents referred to psychodynamic factors in the formulation. Possibly this is because the term is generally understood in the context of the depth psychologies rather than in the wider sense of the psychological and emotional factors surrounding the patient. It is difficult to conceive of meaningful understanding, let alone management, without an appraisal of such influences, inherently uncertain though it may be.

In the view of the authors, the formulation is an analysis of, and an attempt to understand, the situation and the personal world of the individual with a psychological problem, distress or abnormality, in order to help him so far as current knowledge and resources allow. A subsidiary aim is to make an informed prediction about his future, within accepted, if wide, margins of error.

The analysis and the understanding draw on the history, the mental state and the physical examination. They use models of disease and illness, where these apply, and thus consider differential diagnosis and adopt a working diagnosis, if necessary, after further investigations. Aetiological factors are reviewed. The psychodynamics, both intrapsychic and interpersonal, are described so far as possible because they are the vehicle upon which management must be carried. The patient is regarded as part of a social system and that system must also be described and assessed, in order to determine the contribution of significant others and of the environment to the problem and to its alleviation. The options available (physical, psychological and social) in the management are discussed and a course of action selected, together with the person(s) who will carry it out. Finally, the formulation will aim to place the individual case in the context of others requiring services, so that priorities can be allocated.

How the psychiatrist communicates his analysis will obviously depend not only upon himself, but also upon the characteristics of the person(s) receiving that information. Thus, the terms used, the amount of detail, the range of possibilities listed, the certainty with which an opinion is expressed, the length of the communication, etc, will vary considerably, but these are no more than differences of detail within a standard range of conceptual heads.

The present study was not concerned with the MRCPsych examination setting and the replies showed that in the vast majority of cases it was 'real-life' clinical practice which was in the mind of the writer and not the examination, which of necessity is artificial and constrained. Nevertheless, what descriptions of the formulation have been published are directed at trainee psychiatrists, and by implication or explicitly, at the potential examination candidate. This is true of the guidelines of Greenberg and his colleagues in the Bulletin and of the ensuing correspondence.

In the main those guidelines are excellent, indicating a view of patients and of psychiatric practice with which the authors are in almost complete agreement. There are, however, three points on which the present authors differ.

Firstly, it is important always to include a statement on physical examination in a psychiatric formulation in order to avoid overlooking a major source of error. Secondly, the very extensive guidelines seem overwhelming for an examination candidate who is to speak his formulation in five or ten minutes, although they are entirely appropriate for ordinary practice. Perhaps the management and prognosis should be left out of the initial formulation in the examination, to be brought into the discussion by the examiner at a later point. Finally, although the contribution of 'others' is mentioned, the concept of the patient as a part of a dynamic system requiring assessment and management in its own right is not considered, and it should be.

In conclusion, the hypothesis upon which the study was based is supported by the evidence: in day-to-day practice psychiatrists vary a great deal with regard to their notion of the formulation. As psychiatry is such a broad church this is hardly surprising and the nature of the subject virtually precludes uniformity. On the other hand, standardization of the assessment of candidates is of the greatest importance in a professional examination such as the MRCPsych. For this reason a similar survey of College examiners has been carried out; it will be reported separately.

\section{REFERENCES}

Anderson, E. W. \& Trethowan, W. H. (1973) Psychiatry. London: Baillière and Tindall.

Curran, D., Partridge, M. \& Storey, P. B. (1980) Psychological Medicine-An Introduction to Psychiatry (pp. 70-71). Edinburgh: Churchill Livingstone. 
Garrick, T. R. \& Stotzand, N. L. (1982) How to write a psychiatric consultation. American Journal of Psychiatry, 139, 849-55.

Hill, P., Murray, R. \& Thorley, A. (eds) (1979) Essentials of Postgraduate Psychiatry. London: Academic Press.

INSTITUTE OF PsychIATRY (1973) Notes on Eliciting and Recording Information (p. 13). Oxford University Press.

Kendeln, R. E. (1975) The Role of Diagnosis in Psychiatry (pp. 5-7). Oxford: Blackwell Scientific Publications.

Priest, R. G. \& Steinert, J. (1977) Insanity-A Study of Major Psychiatric Disorders (p. 191). Plymouth: McDonald and
Evans.

Royal College of Psychiatrists (1979) Membership Examination Clinical and Oral Examinations. Guidance to Candidates. (Leaflet circulated from the College's Examinations Office.)

Slater, E. \& Roth, M. (1977) Clinical Psychiatry (p. 35). London: Baillière and Tindall.

Sim, M. (1974) Guide to Psychiatry. Edinburgh: Churchill Livingstone.

Tredgold, R. F. \& Wolpf, H. H. (1970) UCH Notes on Psychiatry (p. 9). London: Gerald Duckworth.

\section{Parliamentary News \\ (January 1983-March 1983)}

\section{Grendon Prison: prison patients}

On 9 February 1983 Lord Donaldson of Kingsbridge, the first Chairman of the Board of Visitors at Grendon Prison, initiated a debate on the expressed intention of the Prison Department to increase the number of inmates at Grendon to 270 by March 1983. The present Board of Visitors were concerned that this would result in a fundamental change of function and reduced therapeutic potential at Grendon. Lord Donaldson reviewed the work of Grendon Prison over the years and paid tribute to Dr Gray, the first Medical Superintendent/Governor. Lord Donaldson referred to the work of Professor John Gunn and Graham Robertson and their evaluation of Grendon Prison with their conclusion that the Grendon system achieved a significant psychological and psychiatric improvement in the prisoners selected to go there. Lord Donaldson went on to review the present work of Grendon in detail and concluded that the present population of $\mathbf{2 4 5}$ was dangerously high and should in fact be reduced by at least 20 . He sincerely believed that the present intentions to increase numbers would end by destroying one of the four outstandingly good features of the prison systemthe others being Barlinnie, the Annexe at Wormwood Scrubs and the therapeutic unit at Holloway. Lord Longford also spoke and said that he had no words which were not a condemnation of the Home Office treatment of prisoners who may be described as psychiatric although he recognized the great difficulty of the task. He was concerned about the large number of individuals in prison who should be in a hospital and thought that it might be estimated as 1,000 who were, by most ordinary standards, medical cases. He was followed by Lord Foot and Lord Kagan, both of whom expressed concern, and then by Lord Hooson who said that he was 'filled with dismay'. He spoke warmly of the research that had been carried out at Grendon over the years and could be applied to other penal establishments. Lord Harris of Greenwich referred to the need to reduce the total prison population and discussed the proposal which had been previously made in the Criminal Justice Act to bring down the parole threshhold from twelve months to a lower level. Lord Elton (Parliamentary Under Secretary of State, Home Office) replied that the prison population stood at nearly 44,000 , that is approximately 6,000 higher than the current figure of certified normal accommodation. It was expected to peak at about $\mathbf{4 4 , 7 0 0}$ in April. He said that $\mathbf{4 5 2}$ places in regional secure units were either under construction or now open. This included one unit in the North-East of England which provided 30 places and two further units in the Trent and Western regions with 60 and 30 places respectively which will be opened following commissioning and recruitment of staff. The Home Office were concerned that the unit (C Wing) at Parkhurst Prison had to close in 1979, but the Department had recently been exploring the possibility of reestablishing the unit and of setting up a second similar unit elsewhere. With respect to Grendon, the Home Office did not accept that an increase in the population would inevitably destroy its regime. Grendon was regarded as an essential and a very successful part of the psychiatric services in the prison system and they were committed to ensuring that it continued to provide this service. The longer term aim was to ensure that Grendon was more fully used as a therapeutic establishment. There were plans for posting more permanent staff there and for converting some accommodation.

\section{Mentally handicapped persons}

In a written answer on 24 February 1983, Mr Rossi of the DHSS said that in the period April 1981 to March 1982 the average daily cost per patient to the NHS in a mental handicap hospital was $£ 25$. The daily local authority accommodation cost of maintaining a mentally handicapped resident in local authority accommodation was $£ 12$. These figures relate to England only. 